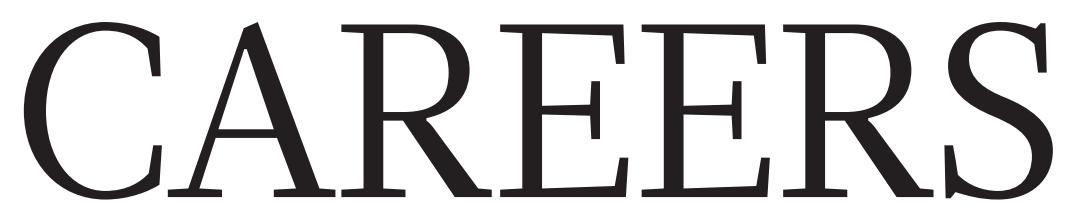

MEDICINE Female authors more likely to address gender gaps in treatment $\mathbf{p . 1 1 9}$
NEED TO KNOW Working out what US PhD

students should be learning p.119
NATUREJOBS For the latest career

listings and advice www.naturejobs.com

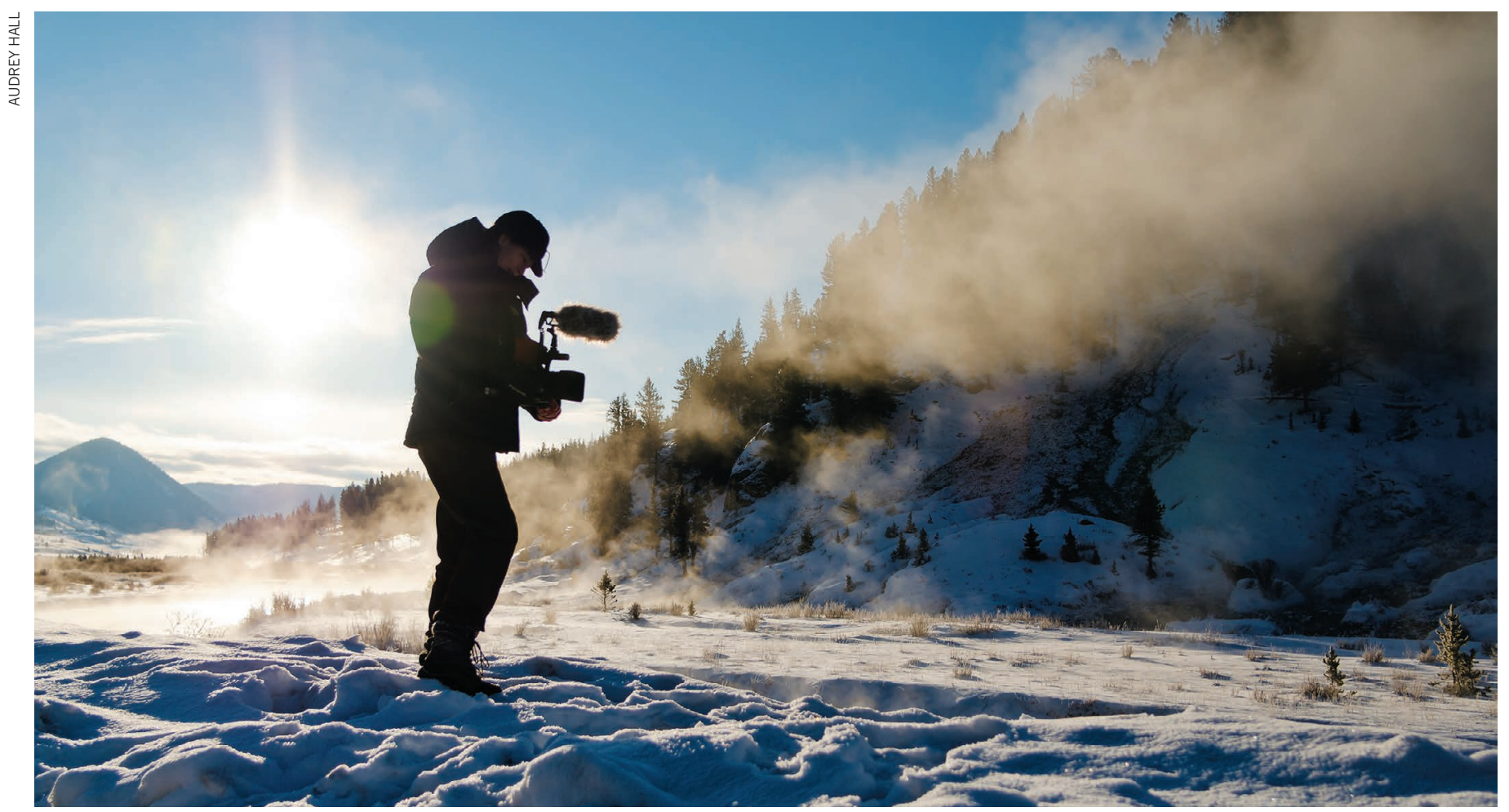

Biologist Stephani Gordon turned to freelance film-making to capture nature and science research on camera.

VISUAL MEDIA

\title{
Science on the screen
}

\section{Film-making offers scientists the chance to transform research into stunning visuals.}

\section{BY ROBERTA KWOK}

S tephani Gordon has filmed squid in the Gulf of California, a nineteenth-century whaling boat in the northwestern Hawaiian Islands and a search for Amelia Earhart's plane in the central Pacific. In 2017, she shot footage off the coast of Mexico of pelagic creatures such as the paper nautilus (Argonauta nouryi) and vampire jellyfish (Vampyrocrossota childressi).

Gordon, sole proprietor of Open Boat Films in Portland, Oregon, spent more than a decade working as a field biologist, studying seabirds, sharks and other marine animals. But from 2004 to 2005 , while working as a marine-ecosystem research specialist at the US National Oceanic and Atmospheric Administration (NOAA) in Honolulu, Hawaii, she served as a field guide for two nature photographers and was impressed by the large audience their images drew.

In December 2005, she learnt from a friend about a graduate programme in science and natural-history film-making at Montana State University in Bozeman, intended for students who have science, engineering or technology backgrounds. "A huge lightbulb went off" after reading the programme description, Gordon remembers. She recalls thinking: "This is what I need to do. This fits me."

Gordon had no experience making videos, but she had taken photographs for her university's student newspaper, and had once considered photojournalism as a career. And she had always thought that science TV programmes

\section{$\rightarrow$ NATURE.COM}

For accompanying videos, see the online story at

go.nature.com/2blrafu should include more field-research details.

Gordon won a place on the course and learnt how to write scripts, direct a production and edit video. She began freelancing during her studies and continued full-time after graduation, working for clients such as National Geographic, the $\mathrm{BBC}, \mathrm{PBS}$ and NOAA. She has no regrets about leaving research behind, even though freelance film-making presents challenges, among them an unstable income. "It just feels like the right medium for me," she says.

Video offers researchers a dynamic way to communicate scientific concepts, ranging from the way microscopic algae tumble through water to dancers enacting Brownian motion. With the rise of mobile devices and a generation that expects online visual content, the demand for videos is booming. YouTube boasts more than 1 billion users, who collectively 
watch about 1 billion hours of video per day, according to the company's website. "There is just a hunger for visual media," says Dennis Aig, programme director of the science film-making course at Montana State University.

Science videos generally aren't as popular as, say, gaming or music clips. But there is a demand for them, Aig says, because they can show research in remote or unusual places, and explain difficult concepts more clearly.

It's easier now for interested researchers to learn the requisite skills and produce content, thanks to science-film-making graduate courses; general science-communication programmes that offer video courses; and shortterm training workshops. Expensive equipment is unnecessary - often, an iPhone and basic accessories will do. Some scientists make outreach videos on the side, whereas others become full-time freelance film-makers, educationalcontent creators or staff members at production companies or non-profit organizations.

Projects such as TV nature documentaries are highly competitive, with limited staff jobs and many freelancers trying to break in. And the work can be strenuous: hauling heavy gear and filming in cold, wet weather are often part of the job. But when the right images, sound and dialogue come together, it is magical, says Charlotte Salvatico, a freelance film-maker, teacher and consultant. She is the Paris coordinator of Imagine Science Films (ISF), a non-profit based in New York City that runs science-film festivals and encourages connections between scientists and film-makers. (Nature sponsored awards at the Imagine Science Film Festival for several years, ending in 2016.)

\section{SCIENTIFIC FINESSE}

Gordon says that her field research prepared her to shoot nature documentaries. As a marine biologist, she performed delicate tasks such as collecting coral eggs with a syringe; jobs such as filming underwater, for example, require the same fine control over instruments. In the field, she grew accustomed to working in remote locations and fixing equipment, and knew how to avoid disturbing wildlife - skills that she uses constantly today. She says that the process behind her current work is similar to field research: collect observations, shape them into a story and distribute the product. "To me, science film-making feels totally equivalent to being a field biologist," she says.

Aig estimates that roughly 1,000-2,000 people with science backgrounds are making films professionally in the United States and Europe. In 2016, ISF launched an online database of science movies called Labocine, which now contains more than 2,000 titles, ranging from documentaries to avant-garde films; of those, about one-fifth were made by scientists, says Nate Dorr, director of programming at ISF. For example, the experimental film The Mirror System depicts a woman who dreams of memories while exploring a neuron 'forest'. It was directed by Eva Zornio, an independent filmmaker with a neuroscience background and based in Geneva, Switzerland. Some research organizations are pushing the medium as well. Celldance, a programme run by the American Society for Cell Biology in Bethesda, Maryland, provides US $\$ 1,000$ grants for scientists to produce videos about their research.

Science-film-making graduate programmes offer a structured route into the industry, and video experience may not be necessary to apply. "We assume they don't know anything," Aig says of students in his programme. Similarly, the science and natural-history film-making graduate programme at the University of Otago in Dunedin, New Zealand, looks for applicants with portfolios demonstrating a creative spark, but another medium such as photography or drawing is acceptable, says Lloyd Spencer Davis, founder of the university's Centre for Science Communication. Other wildlife or environmental-film-making programmes are offered at the American University in Washington DC, the University of Salford, UK, and the University of the West of England in Bristol, UK. Researchers can also enter science journalism or communication programmes that include video

\section{PHONE SKILLS}

\section{Shortcuts to filming}

Researchers can try out film-making without expensive equipment. "You don't need anything fancier than your phone," says Rob Nelson, director of Untamed Science, a non-profit in Charlotte, North Carolina, that makes science videos. And Apple's free editing software iMovie is generally sufficient for beginners. Film-making tutorials are available on the sites Vimeo Video School, Lynda. com, Khan Academy and Untamed Science's YouTube channel Rob \& Jonas' Filmmaking Tips.

Extra equipment might be necessary to gather clear audio. Viewers can tolerate shaky video, but they will stop watching if it's hard to hear the person speaking, says Huw James, founder of Anturus, an adventure-education company in Cardiff, UK, that produces science videos. When interviewing someone on camera, the film-maker should record audio using a separate phone or microphone positioned close to the person. When outdoors, a lavalier microphone with a wind shield is essential, James says.

Amateurs should be prepared to improve through trial and error. "The most crucial thing is being okay with failing quite a lot," James says. "They're not going to look great straight away." R.K. coursework, such as those at Imperial College London or Boston University in Massachusetts.

If graduate school is not an option, researchers can seek unpaid internships on film productions to learn the ropes. For instance, a cephalopod researcher could assist on an octopus documentary by sharing knowledge about the creatures' habitat. Researchers can ask industry contacts for mentor suggestions, or attend film festivals. During the first year of her film-making programme, Gordon approached John Brooks, an independent director of photography and underwater cinematographer, at the Jackson Hole Film Festival in Wyoming, and offered to be his dive assistant. Partly because she was certified as a NOAA diver, he agreed to let her join a film project.

Scientists can also pick up video skills at short workshops or university classes. ScienceFilm in Bowen Island, Canada, for example, holds workshops of 3-12 days to train researchers and other professionals to make videos. Students are not expected to become full-time filmmakers but to use video as a tool, says Colin Bates, the company's co-founder and an ecologist at Quest University Canada in Squamish. For instance, a researcher could create a video of a field or lab technique for a conference presentation to help explain the method, he says. The training could also help scientists to satisfy outreach requirements in grant applications, or to produce video abstracts for papers. Les Chercheurs Font Leur Cinéma (Researchers Make Their Movies), a programme run by Doc'Up, a doctoral-student association in Paris, helps $\mathrm{PhD}$ students in the Île-de-France area to make five-minute movies about their research.

Creating videos allows scientists to better communicate their research to peers and the public, says Sally Warring, a protistologist at the American Museum of Natural History in New York City, who films microbes. She recalls a video made by a team at Harvard Medical School in Boston, Massachusetts, and the Technion-Israel Institute of Technology in Haifa showing the growth of antibiotic-resistant bacteria (go.nature.com/2bd0xjx), which she found more powerful than a graph. And if scientists are issuing a press release about a study, a companion video might pique journalists' interest, she says.

Scientists can dabble using basic equipment (see 'Shortcuts to filming'). Some people start by creating short videos for social media. In 2015, Warring began filming pond microbes under the microscope with her iPhone. Her simple videos captured processes such as green algae producing a colony. Warring posted them on her Instagram account @pondlife_pondlife, which now has more than 48,000 followers.

YouTube allows scientists to explain morecomplex concepts. But videos should still be fast-paced and energetic, because users are easily distracted, says Dianna Cowern, who created the YouTube channel Physics Girl, now funded 


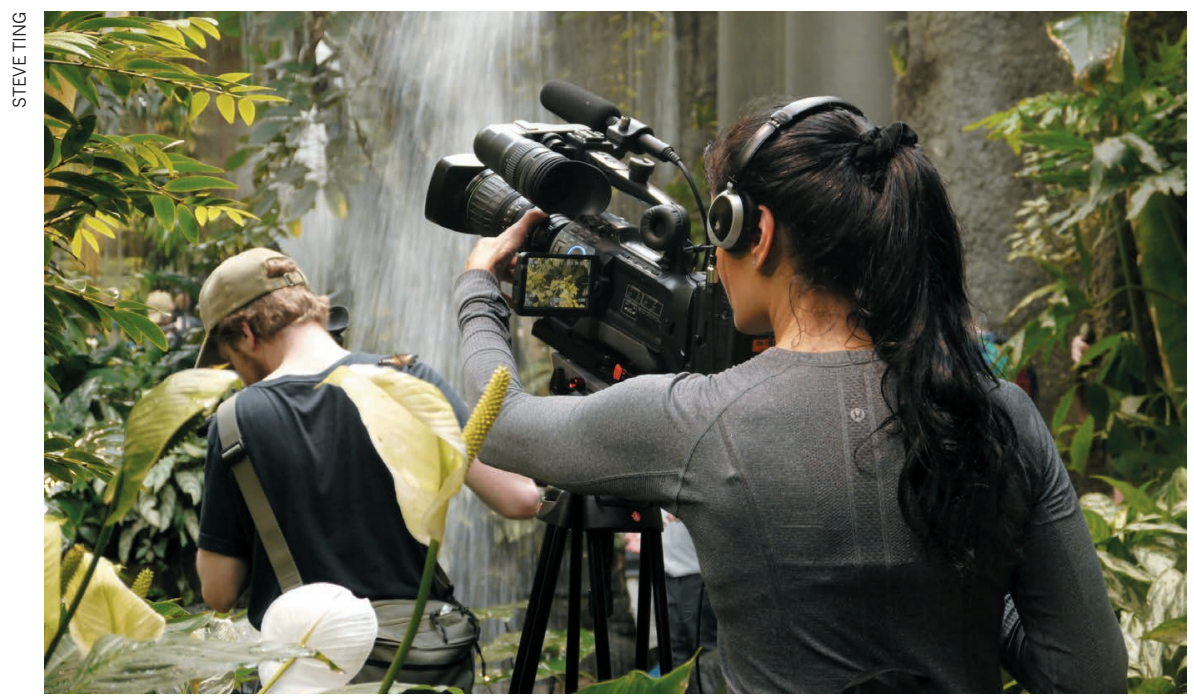

Students on a science film-making course in New Zealand put their skills to the test.

by PBS Digital Studios. "They can click away at any moment," she says. She suggests avoiding standard classroom topics in favour of unusual phenomena - for instance, how sand behaves like a fluid when air bubbles through it.

For more-ambitious projects, scientists can recruit a crew through social media or friends. Warring won funding from ISF to produce a film about lichen; for her six-minute documentary, she recruited film-making friends whom she'd met through graduate school or Instagram. To make a short film during her neuroscience PhD programme, Salvatico

"To me, science film-making feels equivalent to being a field biologist." got a student project grant from the organization Paris Sciences and Letters. A friend at film school introduced her to other students, who became crew members, and Salvatico recruited dancers by e-mailing a conservatory's student office.

But video is time-consuming to produce. Each Instagram video takes Warring several hours, and Cowern's YouTube videos each require about 3-7 days of work. A short documentary can span months.

And although some projects bring in income, returns are typically modest. Warring earns thousands of dollars per year from licensing her photos and videos, and related projects such as creating an exhibition for the Brooklyn Botanic Garden in New York City. Before PBS Digital Studios started supporting Physics Girl, Cowern had about 125,000 subscribers and averaged around $\$ 500-\$ 1,000$ per month in ad revenue. The network noticed her videos and invited her to join them in 2015; she now works full-time on Physics Girl. But reaching a point where YouTube-channel income can support a creator full-time is challenging, she cautions. Cowern produced about 35 videos over 3 years before joining PBS.

Aig estimates that for staff film-makers at production companies, annual salaries are around $\$ 30,000-40,000$ for entry-level positions and $\$ 75,000-80,000$ for middle managers. Top independent film-makers can make hundreds of thousands of dollars per year, but such cases are atypical. Gordon says that her net income is about $60-70 \%$ of what she earned as a scientist.

And film-making is not a cushy gig. "It is as hard as research, maybe even harder, to fully pull off,' Gordon says. Her 2017 expedition off the coast of Mexico hit a snag when the team had to switch research vessels, and the new boat lacked the equipment to support dives for underwater filming. Gordon assembled an in-water studio - custom-made aquariums, lighting and other components - to film animals brought on board instead. Because the species required cold water, she had to work in a walk-in fridge that blew freezing air on her while 5-metre swells buffeted the ship. "It was miserable," she says.

But researchers drawn to the medium can start small — say, with a quick video of fieldwork. "Don't overthink it," says Rob Nelson, director of Untamed Science, a non-profit in Charlotte, North Carolina, that makes science videos. "Just grab a camera."

Roberta Kwok is a freelance writer in Kirkland, Washington.

\section{CORRECTION}

The Turning Point 'Gourmet investigator' (Nature 551, 403; 2017) erroneously stated that Vayu Maini Rekdal's mother was born in Kenya. In fact, she was born in Sweden.

The Careers Feature 'Super catalysts' (Nature 552, 139-140; 2017) misspelled the colloquial term for Margarita

Salas's trainees: they are 'Icfonians', not 'Infonians'.

\section{MEDICAL RESEARCH}

\section{Gender perspectives}

Female co-authorship increases the likelihood that a medical-research paper will address gender-related differences in disease or treatment outcomes, a study in Nature Human Behaviour finds (M. W. Nielsen et al. Nature Hum. Behav. 1, 791-796; 2017). Neglecting these disparities - which affect health outcomes in conditions such as cardiovascular disease and osteoporosis - can have life-threatening consequences, the study adds. The authors analysed more than 1.5 million medical-research papers published between 2008 and 2015. They found that the research was most likely to address gender differences when female scientists were first and last authors. However, female researchers comprised only $40 \%$ of first authors and $27 \%$ of last authors in the papers analysed. This is troubling, the study authors say, because last authors usually lead on identifying, planning and developing research pursuits in health disciplines. Increasing numbers of medical researchers, journal editors and science agencies already acknowledge the importance of including gender analysis in research, the authors note.

\section{EDUCATION}

\section{Tools for post-PhD life}

US graduate programmes are starting to formalize expectations for the skills and competencies that $\mathrm{PhD}$ students should have by the end of their studies, finds a report from the US Council of Graduate Schools (CGS) in Washington DC (see go.nature.com/2aab3gg). In a 2016 survey of its 241 member institutions, the CGS found that $65 \%$ of those responding reported that all or most of their doctoral programmes had developed formal ways to assess whether students are learning specific skills that are relevant to the workplace. The US academic community has long been considering how to address the fact that holders of science $\mathrm{PhDs}$ typically have not learned what they need for non-academic careers (see Nature 543, 277; 2017). Employers outside academia want candidates with transferable skills (see go.nature.com $/ 2 \mathrm{~m} 3 \mathrm{fkfa}$ ), including experience in data science and big data; science policy; governance, risk and compliance; and time, project and budget management. The report recommends that universities work with employers to find out what they look for in job candidates. Universities in Australia, Canada and Europe have developed similar graduateprogramme assessment metrics. 